\title{
Co-infection of HIV and intestinal parasites in rural area of China
}

Li-Guang Tian', Jia-Xu Chen ${ }^{1}$, Tian-Ping Wang ${ }^{2}$, Guo-Jin Cheng ${ }^{3}$, Peter Steinmann ${ }^{4,5}$, Feng-Feng Wang ${ }^{2}$, Yu-Chun Cai', Xiao-Mei Yin², Jian Guo', Li Zhou' and Xiao-Nong Zhou ${ }^{1 *}$

\begin{abstract}
Background: Intestinal parasite infections (IPIs) are among the most significant causes of illness and disease of socially and economically disadvantaged populations in developing countries, including rural areas of the People's Republic of China. With the spread of the human immunodeficiency virus (HIV) among rural Chinese populations, there is ample scope for co-infections and there have been increasing fears about their effects. However, hardly any relevant epidemiological studies have been carried out in the country. The aim of the present survey was to assess the IPI infection status among a representative sample of HIV-positive Chinese in rural Anhui province, and compare the findings with those from a cohort of non-infected individuals.
\end{abstract}

Methods: A case control study was carried out in a rural village of Fuyang, Anhui province, China. Stool samples of all participants were examined for the presence of intestinal parasites. Blood examination was performed for the HIV infection detection and anemia test. A questionnaire was administered to all study participants.

Results: A total of 302 HIV positive and 303 HIV negative individuals provided one stool sample for examination. The overall IPI prevalence of intestinal helminth infections among HIV positives was 4.3\% (13/302) while it was 5.6\% (17/303) among HIV negatives, a non-significant difference. The prevalence of protozoa infections among HIV positives was $23.2 \%$ while the rate was $25.8 \%$ among HIV negatives. The species-specific prevalences among HIV positives were as follows: $3.6 \%$ for hookworm, $0.7 \%$ for Trichuris trichiura, zero for Ascaris lumbricoides, $0.3 \%$ for Clonorchis sinensis, 1.3\% for Giardia intestinalis, 16.2\% for Blastocystis hominis, 1.7\% for Entamoeba spp. and 8.3\% for Cryptosporidium spp.. Cryptosporidium spp. infections were significantly more prevalent among HIV positives (8.3\%) compared to the HIV negative group (3.0\%; $P<0.05)$. Among people infected with HIV, Cryptosporidium spp. was significantly more prevalent among males (12.6\%) than females (4.4\%; $P<0.05)$. According to multivariate logistic regression, the factors significantly associated with parasite infections of the people who were HIV positive included sex (male: $\mathrm{OR}=6.70,95 \% \mathrm{Cl}: 2.030,22.114$ ), younger age (less than 42 years old: $\mathrm{OR}=4.148,95 \% \mathrm{Cl}$ : $1.348,12.761)$, and poor personal hygiene habits ( $\mathrm{OR}=0.324,95 \% \mathrm{Cl}: 0.105,0.994)$.

Conclusions: HIV positive individuals are more susceptible to co-infections with Cryptosporidium spp. than HIV negative people, particularly younger males with poor personal hygiene habits, indicating a need for targeted hygiene promotion, IPI surveillance and treatment.

Keywords: HIV, Intestinal parasites, Helminths, Protozoa, Co-infection, China

\footnotetext{
* Correspondence: ipdzhouxn@sh163.net

${ }^{1}$ National Institute of Parasitic Diseases, Chinese Center for Disease Control and Prevention, WHO Collaborating Centre for Malaria, Schistosomiasis and Filariasis, Key Laboratory of Parasite \& Vector Biology Ministry of Health, Shanghai 200025, China

Full list of author information is available at the end of the article
} 


\section{Background}

Historically, there has been a high prevalence of intestinal parasite infections (IPIs) among human populations in China. Today, IPIs are still common in economically undeveloped rural areas in central China. According to the national survey on important parasitic diseases in the human population completed in 2004, the national prevalence of helminth infections was $21.7 \%$. The prevalence of soil-transmitted helminths (STHs) was 19.6\% (hookworms 6.1\%, Ascaris lumbricoides 12.7\%, Trichuris trichiura 4.6\%), and the estimated number of individuals infected with STHs was 129 million [1]. With the spread of HIV in China, often in rural areas where transmission was fuelled by illegal blood selling, more and more people living with HIV could be coinfected with parasites [2]. However, hardly any epidemiological studies have explored this issue in China [3].

Recent studies have shown that parasitic infections could disturb the balance of anti-HIV immune responses and contributed to HIV replication [4-6], which could accelerate progress to AIDS $[7,8]$. The reduced immune response caused by an HIV infection might also lead to a higher susceptibility to parasitic infections. The high prevalence of certain opportunistic parasites among HIV positives is well known $[9,10]$. Such co-infections present with more severe clinical symptoms compared to parasite infections of otherwise healthy people, and are more difficult to treat [11]. Parasite - HIV co-infections are one of the neglected areas in HIV research although HIV generally has become a major public health concern and research topic in China and beyond. Even since the concerns regarding opportunistic parasite infections among HIV positives have been widely recognized, only few relevant field-epidemiological investigations have been reported in China [3,12].

We carried out a parasitological survey among people living with HIV and non-infected peers in a rural area of Anhui province, China, to understand the epidemiological situation and risk factors for co-infection of HIV and IPIs. The ultimate goal of the study was to provide guidance on the prevention and control of co-infections including treatment needs of HIV/AIDS patients [13], and thus decrease the adverse effects of IPIs on people living with HIV.

\section{Methods}

\section{Study area and population}

The study was conducted in Huangzhuang in the suburbs of Fuyang city, Anhui province, China. In the local clinic for HIV/AIDS treatment a total of 427 HIV-positive people were registered among whom 324 from 12 counties and 126 natural villages were still alive and eligible for inclusion in the study according to the following criteria: age 6-65 years, a signed written informed consent sheet and absence of obvious mental illnesses or other diseases affecting study participation or provision of informed consent. Matching non-HIV infected individuals were recruited among the family members of study participants or, if no suitable controls were available, from their neighborhood. The final study cohort was recruited from 12 villages in Jingiiu district.

\section{Process of the survey}

The study was carried out in the summer of 2008. After a brief public introduction of the study, all residents of the study villages were registered and the participants enrolled in the survey were given a number and a stool collection container with the aim of obtaining a stool sample from each participant. A questionnaire was administered to each participant by fieldworkers from the local Department of AIDS Control and Prevention who had been specifically trained for this task. A blood sample was also collected from all participants and used for HIV testing and hemoglobin, cytokines and CD4 +/CD8+ T-lymphocyte determination.

\section{Laboratory procedures}

The blood samples of all participants were screened for anti-HIV antibodies by an enzyme-linked immunosorbent assay (ELISA; Beijing Jinhao Biologic Medicine Company, China). Positive samples were subject to confirmation by Western blot immunoassay (HIV Blot 2.2 WB; Genelabs Diagnostics, Singapore). Tests were conducted in the local Center for Disease Control and Prevention. Hemoglobin was measured using an automatic biochemical analyzer with the diagnostic threshold for anemia set at less than $130 \mathrm{~g} / \mathrm{L}$ for males and less than $120 \mathrm{~g} / \mathrm{L}$ for females [14]. CD4+/CD8+ T-lymphocytes were tested using FACSCalibur flow cytometry (BD company, USA). Cytokines quantitative ELISA kits (produced by R \& D, U.S.) were used in strict accordance with instructions. The tested cytokines were IL-2, IL-4, IL-10 and IFN- $\gamma$. A. lumbricoides, hookworm, T. trichiura and Clonorchis sinensis infections were identified by the Kato-Katz technique [15]. Three Kato-Katz thick smears were prepared from each stool sample. Since hookworm eggs clear very rapidly, the Kato-Katz slides were each read twice, one within 30 mins and one within the hour. Strongyloides stercoralis was diagnosed using the Charcoal culture method [16]. G. intestinalis and Entamoeba spp. were diagnosed by the Lugol's iodine method [1]. B. hominis was diagnosed using an in vitro culture method [17] and Cryptosporidium spp. was detected by modified acid-fast staining [18]. Diagnoses of parasite infections were conducted by staff from the National Institute of Parasitic Diseases, Chinese Center for Disease Control and Prevention together 
with staff from the Institute of Parasitic Diseases of Anhui province.

\section{Statistical analysis}

EpiData 3.1 was used to establish a database and for double-entry data input by two different individuals. After validation of the database, two identical datasets were obtained, of which one was used for all subsequent analyses. The Student's T-test was employed to test differences in means of age between the HIV positive group and HIV negative group. Univariate statistical analysis was performed using the $\chi^{2}$ test, and the variables with $P$ values less than 0.3 in univariate analysis were included in the multivariate model. Multivariate logistic regression modeling was employed to analyze the relationship of socio-demographic, behavioral and immune variables with parasite infection status. All statistical analyses were performed using the SAS 9.1 package.

\section{Ethical considerations}

The study protocol was approved by the institutional review board of the National Institute of Parasitic Diseases, Chinese Center for Disease Control and Prevention in Shanghai. Participants were contacted through the village leaders and the objectives, procedures, and potential risks were carefully explained to all potential participants. Interested individuals provided written informed consent in person or through their parents (in the case of minors) before inclusion in the study. All participants were offered professional counseling before and after HIV testing by staff of the local AIDS prevention and treatment agencies, and all diagnostic results were kept strictly confidential. Free deworming drugs (albendazole, praziquantel) were offered to all participants found to be infected with helminths through local health care institutions.

\section{Results}

\section{Study cohort}

A total of 624 people were recruited, including 309 HIV positives and 315 HIV negative controls. Stool samples were submitted by 605 individuals and blood samples were collected from 585 while questionnaires were answered by 601 participants. Complete data were available from 552 people who had provided stool and blood samples as well as answered the questionnaires (Figure 1).

Among the 605 individuals who had submitted stool samples were 302 HIV positive and 303 HIV negative individuals. The HIV positives comprised 143 (47.4\%) males and 159 (52.6\%) females and their mean $( \pm$ SD) age was $42.8( \pm 1.2)$ years. Among the 303 HIV negative individuals, $144(47.5 \%)$ were male and 159 (52.5\%) were female and their mean $( \pm \mathrm{SD})$ age was $41.5( \pm 1.3)$ years. No statistically significant difference in age was found between HIV positives and negatives ( $\mathrm{T}$-Tests (Pooled), $\mathrm{t}=-1.53 ; P>0.05 ;$ Table 1 ).

\section{Parasitic infections}

The overall prevalence of intestinal helminth infections was $4.8 \%(29 / 605)$. Hookworm were the most common parasites with $4.0 \%(24 / 605)$, followed by $T$. trichiura and C. sinensis (both $0.5 \% ; 3 / 605)$. S. stercoralis infections were not found (Table 2). People tested HIV positive were infected by hookworm, T. trichiura and $C$. sinensis at a rate of $3.6 \%(11 / 302), 0.7 \%(2 / 302)$ and $0.3 \%(1 / 302)$ respectively, with no significant difference between infection status with any of these intestinal helminths and HIV serostatus. A. lumbricoides infections were not found among HIV positives.

The overall prevalence of intestinal protozoa was $24.1 \%(146 / 605)$. B. hominis was diagnosed most often (19.2\%; 116/605), followed by Cryptosporidium spp. which was found in $5.6 \%(34 / 605)$ of all study participants. HIV positives were infected with B. hominis, Cryptosporidium spp., G. intestinalis and Entamoebae spp. at a rate of $16.2 \%(49 / 302), 8.3 \%$ (25/302), 1.3\% (4/ $302)$ and $1.7 \%(5 / 302)$ respectively. A significant difference between rates among HIV positives and negatives was only found in the case of Cryptosporidium spp. infections, which were more common among HIV positives $(P<0.05$; Table 2$)$. Significantly more of these Cryptosporidium spp. infected HIV positives were males (prevalence: 12.6\%) compared with females (prevalence 4.4\%; $P=0.010)$.

\section{Multiparasitism}

The prevalence of intestinal parasite infections among the HIV positives was $26.2 \%$. Most common were single species infections (66 out of 79 or $83.5 \%$ of the parasiteinfected HIV positive individuals) while $9(11.4 \%)$ were infected with two species concurrently and $3(3.8 \%)$ with three species. One individual was infected with four intestinal parasite species concurrently.

\section{Risk factors for coinfection with HIV and Cryptosporidium} spp. or B. hominis

Among 263 HIV positives that had answered the questionnaire, Cryptosporidium spp. prevalence was significantly higher among males than females $(\mathrm{OR}=6.70$, 95\% CI: $2.03-22.11$ ) and those younger than 42 years $(\mathrm{OR}=4.15,95 \% \mathrm{CI}: 1.35$ - 12.76). Individuals were at lower risk if they had IL-2 less than $77 \mathrm{pg} / \mathrm{ml}(\mathrm{OR}=$ $0.23,95 \% \mathrm{CI}: 0.08-0.67)$ or good hygiene habits $(\mathrm{OR}=$ 0.32, 95\%CI: $0.11-0.99$; Table 3). There was also a significant difference in the prevalence of $B$. hominis between females $(21.9 \%)$ and males $(11.9 \%, \mathrm{p}<0.05)$ in 


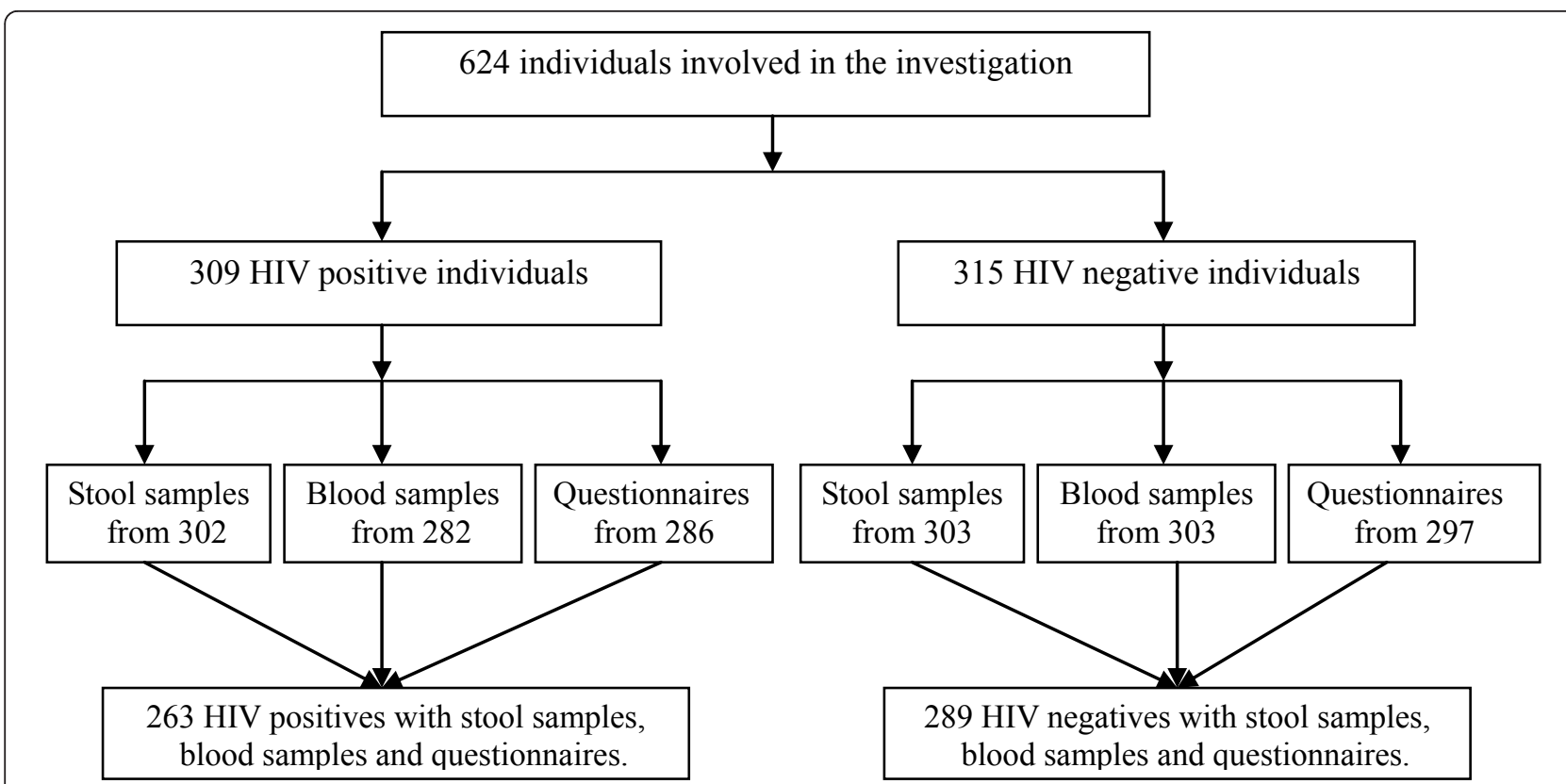

Figure 1 Participation in a survey on co-infections of HIV and intestinal parasites in a rural area of Fuyang city, Anhui province, People's Republic of China.

Table 1 Demographic information of the study participants.

\begin{tabular}{|c|c|c|}
\hline variable & $\begin{array}{l}\text { HIV-positive }(\mathbf{n}= \\
302) \\
\mathrm{N}(\%)\end{array}$ & $\begin{array}{l}\text { HIV-negative }(n= \\
303) \\
N(\%)\end{array}$ \\
\hline \multicolumn{3}{|l|}{ Sex } \\
\hline male & $143(47.4 \%)$ & $144(47.5 \%)$ \\
\hline female & $159(52.6 \%)$ & $159(52.5 \%)$ \\
\hline Average age* (year) & $42.8(41.6,44.0)$ & $41.5(40.2,42.7)$ \\
\hline \multicolumn{3}{|l|}{ Agricultural household* } \\
\hline yes & $258(90.2 \%)$ & $260(87.5 \%)$ \\
\hline no & $28(9.8 \%)$ & $37(12.5 \%)$ \\
\hline \multicolumn{3}{|l|}{ Ethnicity* } \\
\hline Han & 284(99.3\%) & 293(98.6\%) \\
\hline Others & $2(0.7 \%)$ & $4(1.4 \%)$ \\
\hline \multicolumn{3}{|l|}{ Marriage status* } \\
\hline single & $6(2.1 \%)$ & $16(5.4 \%)$ \\
\hline married & $280(97.9 \%)$ & $281(94.6 \%)$ \\
\hline \multicolumn{3}{|l|}{ Educational status* } \\
\hline illiterate & $91(31.8 \%)$ & $72(24.2 \%)$ \\
\hline primary school & $148(51.8 \%)$ & $100(33.7 \%)$ \\
\hline junior high school & $45(15.7 \%)$ & $110(37.0 \%)$ \\
\hline high school & $2(0.7 \%)$ & $15(5.1 \%)$ \\
\hline $\begin{array}{l}\text { college graduates and } \\
\text { above }\end{array}$ & 0 & 0 \\
\hline \multicolumn{3}{|l|}{ Occupation* } \\
\hline student & $2(0.7 \%)$ & $7(2.4 \%)$ \\
\hline farmer & 283(98.9\%) & 286(96.3\%) \\
\hline worker & $1(0.4 \%)$ & $4(1.3 \%)$ \\
\hline
\end{tabular}

* HIV positives $n=286 ;$ HIV negatives $n=297$ people who lived with an HIV positive person. The multivariate logistic regression analysis showed that nutritional status was significantly associated with $B$. hominis infection $(\mathrm{OR}=0.26,95 \%$ CI: 0.07 - 0.95; Table 4).

\section{Discussion}

Among the 605 individuals included in the present study, the prevalence of intestinal helminths was $4.8 \%$, with hookworm being the most common species, followed by $T$. trichiura and $C$. sinensis. The prevalence of A. lumbricoides was $0.3 \%$. These values are considerably lower than those reported from the nationwide survey of important human parasites in China conducted from 2001 to 2004 where the prevalence of hookworm was $6.1 \%$ and that of $A$. lumbricoides $12.7 \%$ [1]. The economical development of the country resulting in increased urbanization, infrastructure development and increased health consciousness [19] including a reduction of nightsoil use as well as a relatively old study population (average age 42 years) probably all contributed to this apparent decline.

It has been argued that a HIV infection would increase the risk of intestinal helminth infection [20,21], but the results of the present study do not support this claim, consistent with results reported by Nielsen et al. $[22,23]$. One reason might be that HIV positive individuals change their health-related behavior more radically than their HIV negative peers as they received much more health care attention following the HIV diagnosis. The measured prevalence of $B$. hominis was 
Table 2 Parasitic infections of HIV positive and HIV negative study participants

\begin{tabular}{|c|c|c|c|c|}
\hline Parasite species & $\begin{array}{l}\text { HIV positives } \\
(n=302) \\
\% \text { (No. positive) }\end{array}$ & $\begin{array}{l}\text { HIV negatives } \\
(\mathrm{n}=303) \\
\% \text { (No. positive) }\end{array}$ & $\chi^{2}$ value & $P$ value \\
\hline A. lumbricoides & 0 & $0.66(2)$ & & $0.4992^{*}$ \\
\hline Hookworm & $3.64(11)$ & $4.29(13)$ & 0.1667 & 0.6830 \\
\hline T. trichura & $0.66(2)$ & $0.33(1)$ & & $0.6238^{*}$ \\
\hline C. sinensis & $0.33(1)$ & $0.66(2)$ & & $1.0000^{*}$ \\
\hline Helminths & $4.30(13)$ & $5.30(16)$ & 0.3156 & 0.5742 \\
\hline B. hominis & $16.23(49)$ & $22.11(67)$ & 3.3825 & 0.0659 \\
\hline G. intestinalis & $1.32(4)$ & $0.66(2)$ & & $0.4504^{*}$ \\
\hline Entamoebae & $1.66(5)$ & $0.99(3)$ & & $0.5045^{*}$ \\
\hline Cryptosporidium spp. & $8.28(25)$ & $2.97(9)$ & 8.0399 & 0.0046 \\
\hline Protozoa & $23.2(70)$ & $25.80(76)$ & 0.2994 & 0.5843 \\
\hline
\end{tabular}

* tested by Fisher exact test, others tested by chi-square test

Table 3 Multivariate logistic regression analysis of risk factors for HIV and Cryptosporidium spp.coinfection.

\begin{tabular}{llllll}
\hline Variables & Regression coefficient & Standard Error & OR value $(\mathbf{9 5} \% \mathrm{Cl})$ & $\boldsymbol{\chi}^{\mathbf{2} \text { value }}$ & $\boldsymbol{P}$ value \\
\hline male $(1=$ yes, $0=$ no $)$ & 1.9022 & 0.6092 & $6.700(2.030,22.114)$ & 9.7496 & 0.0018 \\
$\begin{array}{l}\text { age }<42 \text { years } \\
(1=\text { yes, } 0=\text { no })\end{array}$ & 1.4225 & 0.5734 & $4.148(1.348,12.761)$ & 6.1551 & 0.0131 \\
$\begin{array}{l}\text { IL-2 }<77(\mathrm{pg} / \mathrm{ml}) \\
(1=\text { yes, } 0=\text { no })\end{array}$ & -1.4872 & 0.5573 & $0.226(0.076,0.674)$ & 7.1208 & 0.0076 \\
$\begin{array}{l}\text { Good habits } \\
(1=\text { yes, } 0=\text { no })\end{array}$ & -1.1275 & 0.5724 & $0.324(0.105,0.994)$ & 3.8803 & 0.0489 \\
\hline
\end{tabular}

$19.2 \%$, higher than other values reported from China [24-28] but consistent with the findings from other studies where a similar diagnostic approach was followed $[29,30]$. In contrast to reports that HIV positives were more susceptible to $B$. hominis [31,32], no significant difference in $B$. hominis prevalences between HIV positives and HIV negatives was found in the present study. Interestingly, the $B$. hominis prevalence among females was significantly higher than among males in the HIV positive group but no such difference was observed in the HIV negative population.

The only parasite that was found significantly more often among HIV positives than among HIV negatives was Cryptosporidium spp., confirming the findings of numerous other studies [33-35]. According to the multivariate logistic regression analysis, males younger than 42 years and with poor hygiene habits were particularly at risk of Cryptosporidium spp. infection. This mirrors findings by Hunter et al. [36]. Thus, this population should receive particular attention with regard to hygiene education and targeted anti-parasitic treatment.

In this present study, we find that the people with IL$2 \geq 77(\mathrm{pg} / \mathrm{ml})$ were more susceptible to coinfection with HIV and Cryptosporidium spp., which indicate that T lymphocytes are involved in the immune response to the co-infection, although a decrease of IL-2 was observed with the HIV infection. The mechanism needs further study in the future, since IL-2 has a key role in $\mathrm{T}$ lymphocyte proliferation and activity and is fundamental to a human protective immune response [37].

A number of Cryptosporidium species infect humans, namely C. parvum, C. hominis, C. muri and C. meleagridis [38-42]. More work is needed to identify the particular Cryptosporidium species and genotypes prevalent in China.

Table 4 Multivariate logistic regression analysis of risk factors for HIV and B.hominis coinfection

\begin{tabular}{|c|c|c|c|c|c|}
\hline Variables & Regression coefficient & Standard Error & OR value $(95 \% \mathrm{Cl})$ & $\chi^{2}$ value & $P$ value \\
\hline Male $(1=$ yes, $0=$ no $)$ & -0.6713 & 0.3643 & $0.511(0.250,1.044)$ & 3.3967 & 0.0653 \\
\hline $\begin{array}{l}\mathrm{IL}-2<77(\mathrm{pg} / \mathrm{ml}) \\
(1=\text { yes, } 0=\text { no })\end{array}$ & 0.4622 & 0.3587 & $0.630(0.312,1.272)$ & 1.6609 & 0.1975 \\
\hline $\begin{array}{l}\text { Good nutrition } \\
(1=\text { yes, } 0=\text { no })\end{array}$ & -1.3350 & 0.6525 & $0.263(0.073,0.945)$ & 4.1861 & 0.0408 \\
\hline $\begin{array}{l}\text { Good habit } \\
(1=\text { yes, } 0=\text { no })\end{array}$ & -0.6422 & 0.3824 & $0.526(0.249,1.113)$ & 2.8202 & 0.0931 \\
\hline
\end{tabular}




\section{Conclusions}

HIV positive individuals are more susceptible to coinfections with Cryptosporidium spp. than HIV negative people, particularly younger males with poor personal hygiene habits, indicating a need for targeted hygiene promotion, IPIs surveillance and treatment.

\section{Acknowledgements}

The study participants are gratefully acknowledged for their collaboration, and the staff at Anhui Institute of Parasitic Disease Control is thanked for valuable technical assistance throughout the study. We are grateful to the Huangzhuang AIDS Working Group (Ding Zi-Qiang, Zhang Lun, Zhang ZiJun, and Sun Yan-Ping) for providing professional HIV counseling to the study participants, and the Hanshou Center for Disease Control and Prevention (Ouyang Shan-Wen) is thanked for collaboration and support. The study was funded through the National S \& T Mayor Project (grant no. 2008ZX10004-011), and UNICEF/UNDP/World Bank/WHO Special Programme on Research and Training in Tropical Diseases.

\section{Author details}

'National Institute of Parasitic Diseases, Chinese Center for Disease Control and Prevention, WHO Collaborating Centre for Malaria, Schistosomiasis and Filariasis, Key Laboratory of Parasite \& Vector Biology Ministry of Health, Shanghai 200025, China. ${ }^{2}$ Anhui Institute of Parasitic Disease Control, Wuhu 241000, China. ${ }^{3}$ Fuyang Center for Disease Control and Prevention, Fuyang 236000, China. ${ }^{4}$ Department of Epidemiology and Public Health, Swiss Tropical and Public Health Institute, 4051 Basel, Switzerland. ${ }^{5}$ University of Basel, 4051 Basel, Switzerland.

\section{Authors' contributions}

Conceived and designed the experiments: L-GT X-NZ J-XC T-PW. Performed the experiments: L-GT F-FW JG X-MY W-DW L-HL. Analyzed the data: L-GT. Contributed reagents/materials/analysis tools: G-JC Y-CC LZ. Wrote the paper: L-GT PS X-NZ. All authors read and approved the final version of the manuscript.

\section{Competing interests}

The authors declare that they have no competing interests.

Received: 15 November 2011 Accepted: 13 February 2012

Published: 13 February 2012

\section{References}

1. $X u L Q, C h e n ~ Y D$, Sun FH: A national survey on current status of the important parasitic diseases in human population. Chin J Parasitol Parasit Dis 2005, 23:332-340, (in Chinese).

2. Shao Y: AIDS epidemic at age 25 and control efforts in China. Retrovirology 2006, 3:87.

3. Tian LG, Steinmann P, Chen JX, Chen SH, Zhou XN: HIV/AIDS, parasites and co-infections: publication patterns in China. Parasit Vectors 2009, 2:31.

4. Newton CR: Interaction between Plasmodium falciparum and human immunodeficiency virus type 1 on the central nervous system of African children. J Neurovirol 2005, 11:Suppl 3: 45-51.

5. Gopinath R, Ostrowski M, Justement SJ, Fauci AS, Nutman TB: Filarial infections increase susceptibility to human immunodeficiency virus infection in peripheral blood mononuclear cells in vitro. J Infect Dis 2000, 182:1804-1808.

6. Harms G, Feldmeier H: HIV infection and tropical parasitic diseases deleterious interactions in both directions? Trop Med Int Health 2002, 7:479-488.

7. Karanja DM, Colley DG, Nahlen BL, Ouma JH, Secor WE: Studies on schistosomiasis in western Kenya: I: Evidence for immune-facilitated excretion of schistosome eggs from patients with Schistosoma mansoni and human immunodeficiency virus coinfections. Am J Trop Med Hyg 1997, 56:515-521.

8. Tawill SA, Gallin M, Erttmann KD, Kipp W, Bamuhiiga J: Impaired antibody responses and loss of reactivity to Onchocerca volvulus antigens by HIV- seropositive onchocerciasis patients. Trans R Soc Trop Med Hyg 1996, 90:85-89.

9. Karp CL, Auwaerter PG: Coinfection with HIV and tropical infectious diseases. II: Helminthic, fungal, bacterial, and viral pathogens. Clin Infect Dis 2007, 45:1214-1220.

10. Nielsen NO, Simonsen PE, Dalgaard P, Krarup H, Magnussen P: Effect of diethylcarbamazine on HIV load, CD4\%, and CD4/CD8 ratio in HIVinfected adult Tanzanians with or without lymphatic filariasis: randomized double-blind and placebo-controlled cross-over trial. Am J Trop Med Hyg 2007, 77:507-513.

11. Corbett EL, Steketee RW, ter Kuile FO, Latif AS, Kamali A: HIV-1/AIDS and the control of other infectious diseases in Africa. Lancet 2002, 359:2177-2187.

12. Tian $L G$, Zhou XN: Intestinal parasitic infections neglected in the HIV/ AIDS patients. Chin J Parasitol Parasit Dis 2008, 26:376-381 (in Chinese).

13. Fincham JE, Markus MB, Adams VJ: Could control of soil-transmitted helminthic infection influence the HIV/AIDS pandemic. Acta Trop 2003, 86:315-333.

14. Unicef UNU. WHO: Iron deficiency anaemia: assessment, prevention, and control. A guide for programme managers Geneva; 2001, WHO.

15. Katz N, Chaves A, Pellegrino J: A simple device for quantitative stool thick-smear technique in schistosomiasis mansoni. Rev Inst Med Trop Sao Paulo 1972, 14:397-400.

16. Koga K, Kasuya S, Khamboonruang C, Sukhavat K, leda M: A modified agar plate method for detection of Strongyloides stercoralis. Am J Trop Med Hyg 1991, 45:518-521.

17. Taamasri P, Leelayoova S, Rangsin R, Naaglor T, Ketupanya A: Prevalence of Blastocystis hominis carriage in Thai army personnel based in Chonburi, Thailand. Mil Med 2002, 167:643-646.

18. Arikan $S$, Ergüven $S$, Aky $n$ Y, Günalp A: Cryptosporidiosis in immunocompromised patients in a Turkish university hospital. Acta Microbiol Immunol Hung 1999, 46:33-40.

19. Qu FY: Historical review on the development of medical parasitology in China during the years of 1871-2006. Chin J Parasitol Parasit Dis 2007, 25:259-273, (in Chinese).

20. Mohandas K, Sehgal R, Sud A, Malla N: Prevalence of intestinal parasitic pathogens in HIV-seropositive individuals in Northern India. Jpn J Infect Dis 2002, 55:83-84.

21. Wiwanitkit V: Intestinal parasitic infections in Thai HIV-infected patients with different immunity status. BMC gastroenterol 2001, 1:3.

22. Nielsen NO, Simonsen PE, Magnussen P, Magesa S, Friis H: Cross-sectional relationship between HIV, lymphatic filariasis and other parasitic infections in adults in coastal northeastern Tanzania. Trans $R$ Soc Trop Med Hyg 2006, 100:543-550.

23. Nielsen NO, Friis $\mathrm{H}$, Magnussen $\mathrm{P}$, Krarup $\mathrm{H}$, Magesa S: Co-infection with subclinical HIV and Wuchereria bancrofti, and the role of malaria and hookworms, in adult Tanzanians: infection intensities, CD4/CD8 counts and cytokine responses. Trans R Soc Trop Med Hyg 2007, 101:602-612.

24. Zhang XP, Li LH, Zhu Q, Fu YH, Ma XJ: Investigation on the infection of Blastocystis hominis in various populations in Shanghai, China. J Pathog Biol 2008, 3:693-710, (in Chinese).

25. Su ZL, Su SL, Wu ZF, Miao H, Miao Y, Xie QJ, Zhang QS: Survey epidemiology of Blastocystis hominis infection in Ganzhou. $J$ Pathog Biol 2008, 3: 142-143, (in Chinese).

26. Zhang HW, Yan QY, He L, Su YP, Li W: Survey on asymptomtic Blastocystis hominis and its PCR identification. J Med Forum 2006, 27:32-36, (in Chinese).

27. Li CP, Wang J: Epidemiology investigation of Blastocystis hominis in Huainan areas. NEGATIVE 2002, 23:1480-1482, (in Chinese).

28. Zhou HF, Yan JL, Li JY: Current status of the important parasitic diseases in Luwan district. J Trop Med 2006, 6:1203-1204 (in Chinese).

29. Li LH, Zhang XP, Lv S, Zhang L, Yoshikawa H: Cross-sectional surveys and subtype classification of human Blastocystis isolates from four epidemiological settings in China. Parasitol Res 2007, 102:83-90.

30. Li LH, Zhou XN, Du ZW, Wang XZ, Wang LB: Molecular epidemiology of human Blastocystis in a village in Yunnan province, China. Parasitol Int 2007, 56:281-286.

31. Pinlaor S, Mootsikapun P, Pinlaor P, Pipitgool V, Tuangnadee R: Detection of opportunistic and non-opportunistic intestinal parasites and liver flukes in HIV-positive and HIV-negative subjects. Southeast Asian J Trop Med Public Health 2005, 36:841. 
32. Gassama A, Sow PS, Fall F, Camara P, Philippe H: Ordinary and opportunistic enteropathogens associated with diarrhea in Senegalese adults in relation to human immunodeficiency virus serostatus. Int $J$ Infect Dis 2001, 5:192-198.

33. Deodhar L, Maniar JK, Saple DG: Cyclospora infection in acquired immunodeficiency syndrome. J Assoc Physicians India 2000, 48:404-406.

34. Garcia C, Rodriguez E, Do N, López de Castilla D, Terashima A, Gotuzzo E, Terashima A: Intestinal parasitosis in patients with HIV-AIDS. ReV Gastroenterol Peru 2006, 26:21-24.

35. Noureldin MS, Shaltout AA, El Hamshary EM, Ali ME: Opportunistic intestinal protozoal infections in immunocompromised children. J Egy Soc Parasitol 1999, 29:951.

36. Hunter PR, Hughes S, Woodhouse S, Syed Q, Verlander NQ, Chalmers RM, Morgan K, Nichols G, Beeching N, Osborn K: Sporadic cryptosporidiosis case-control study with genotyping. Emerg Infect Dis 2004, 10:1241-1249.

37. Benczik M, Gaffen SL: The interleukin (IL)-2family cytokines: survival and proliferation signaling pathways in T lymphocytes. Immunol Invest 2004, 33:109-142.

38. Cama V, Gilman RH, Vivar A, Ticona E, Ortega Y, Bern C, Xiao L: Mixed Cryptosporidium infections and HIV. Emerg Infect Dis 2006, 12:1025-1028.

39. Tanriverdi S, Arslan M, Akiyoshi DE, Tzipori S, Widmer G: Identification of genotypically mixed Cryptosporidium parvum populations in humans and calves. Mol Biochem Parasitol 2003, 130:13-22.

40. Xiao L, Ryan UM: Cryptosporidiosis: an update in molecular epidemiology. Curr Opinion Infect Dis 2004, 17:483-490.

41. Llorente MT, Clavel A, Goñi MP, Varea M, Seral C, Becerril R, Suarez L, Gómez-Lus R: Genetic characterization of Cryptosporidium species from humans in Spain. Parasitol Int 2007, 56:201-205.

42. Donato Traversa: Evidence for a new species of Cryptosporidium infecting tortoises: Cryptosporidium ducismarci. Parasite Vectors 2010, 3:21.

doi:10.1186/1756-3305-5-36

Cite this article as: Tian et al: Co-infection of HIV and intestinal parasites in rural area of China. Parasites \& Vectors 2012 5:36.

\section{Submit your next manuscript to BioMed Central and take full advantage of:}

- Convenient online submission

- Thorough peer review

- No space constraints or color figure charges

- Immediate publication on acceptance

- Inclusion in PubMed, CAS, Scopus and Google Scholar

- Research which is freely available for redistribution

Submit your manuscript at www.biomedcentral.com/submit 